TECHNOLOGICAL LEARNING, TECHNOLOGICAL SUBSTITUTION, AND TECHNOLOGICAL CHANGE

Jennifer M. Robinson

International Institute for Applied Systems Analysis, Laxenburg, Austria

RR-82-31

August 1982

Reprinted from Technological Forecasting and Social Change, volume 18 (1980)

INTERNATIONAL INSTITUTE FOR APPLIED SYSTEMS ANALYSIS

Laxenburg, Austria 
Research Reports, which record research conducted at IIASA, are independently reviewed before publication. However, the views and opinions they express are not necessarily those of the Institute or the National Member Organizations that support it.

Reproduced with permission from the author and Technological Forecasting and Social Change $18: 39-49,1980$.

Copyright (c) J.M. Robinson, 1980.

All rights reserved. No part of this publication may be reproduced or transmitted in any form or by any means, electronic or mechanical, including photocopy, recording, or any information storage or retrieval system, without permission in writing from the copyright holder. 


\section{FOREWORD}

The International Institute for Applied Systems Analysis has, for a number of years, included in its program of work studies of technological innovation and the socio-economic issues associated with this process. Jennifer Robinson, a Visiting Scholar at IIASA during 1979 and 1980 was a leading contributor to these studies, not only during that period, but also during later extended visits, and by means of computer conferencing, an innovative technology in which IIASA has played a development role for international research activities.

This paper is one of the products of her work.

ALEC M. LEE

Chairman

Management and Technology Area 


\title{
Technological Learning, Technological Substitution, and Technological Change
}

\author{
JENNIFER M. ROBINSON
}

PREFATORY NOTE: The innovation process, defined here to incorporate the full cycle from invention to full commercialization, is slow. It cannot be encompassed with time horizons of less than 20 years. Many innovations require half a century or more to reach commercial maturity.

Management of the innovation process is critical to the management of technology, but the slowness of the process makes it difficult for conventional economists or policy makers, who typically consider 15 years a long-term forecast or plan, to understand or control. The situation, in short, is one in which the absence of theoretical understanding limits the effectiveness of managerial practice. Accordingly one appropriate niche for applied systems analysis in this case is the development, application, and testing of theoretical models.

Toward this end the innovation task force of IIASA's management and technology area is studying the mechanisms of technological substitution. One phase of this work is being conducted through construction and analysis of a series of dynamic simulation models, TECH1, TECH2, . ., TECHN

The present working paper is one of a series describing these models. It puts work described in related papers into a broad, somewhat philosophical context. First it brings together into a common framework the notions of basic versus improvement innovations and learning curves and process versus product innovation. Second, it looks at the relationship of the individual technological substitution to the process of technological change as a whole. It is complementary to working papers by the same author entitled "Technological Shift: A Cybernetic Exploration [11]," a semitechnical description of TECHI, and "Technological Shift: A Graphical Exploration of Progress Functions, Technological Costs and Their Effects on Technological Substitution [12]."

Later papers in the series will describe TECH2, a variant of TECH restructured to assume a planned economy rather than a free market competition, and the application of TECH to historically observed technological substitutions.

\begin{abstract}
From a simple dynamic model of competition between product lines it is shown that the shape of learning curves has a powerful influence on the dynamics of technological substitution. Learning of both production efficiency and marketing efficiency is considered. It is asserted that both types of learning are important and that the two are complementary. It is further speculated that production learning is probably more important for commodities and in situations of low per capita income, whereas market learning gains ascendancy in cases of high income and specialized and diversified product lines. In closing, it is noted that simple competitive models are misleading, first because complementarities and coevolutionary processes are probably as important in the
\end{abstract}

JENNIFER M. ROBINSON is a research scholar with the IIASA management and technology area task force on technological innovation. Apprenticed in systems analysis under D. H. Meadows, she received her M.S. in Food and Agricultural Policy from the University of Illinois in 1977. She has worked on the presidential commission study Global 2000.

(C) J. M. Robinson, 1980 
overall development of technology as are competitive processes, and second because optimization of the technological system's parts does not guarantee improvement of the performance of the system as a whole.

\section{Introduction}

Most authors appear to accept the notion that technological change is at least partially an optimizing process. There also seems to be a general consensus that optimization takes place through technological innovation on different levels. On a low and more or less continuous level, small incremental improvements are made to existing processes and products. On a higher and relatively discontinuous level the invention of radically new technologies (basic innovations) leads to substitution of more adaptive technologies for less adaptive ones. There is presently no unified theory associating various levels of technological optimization with functional forms. Nonetheless, in common usage lowerlevel "improvement innovations" appear to correspond to the functional forms called "learning curves" or "progress functions," while higher-level "basic innovations" correspond to the typically S-shaped substitution curves. The term "technological change" likewise can be equated to the net effect of multiple events of technological progress (learning) and technological substitution occurring simultaneously.

This paper puts the three levels together. It begins by posing a conceptual model of technological substitution and investigating the role that efficiency learning (i.e., incremental cost reduction) plays in the substitution process. It then expands the model to consider the roles of product improvement and other sorts of learning. It concludes with an examination of technological change as a consequence of multiple technological substitutions. The last section stresses the concept that optimization of the parts may not lead to optimization of the whole-in other words, that society cannot depend on technological progress and technological substitution to lead to socially desirable forms of technological change.

The model assumes a free market in which price is determined by supply and demand and supply and demand are affected by price. This by no means precludes using the model to examine technological substitution in planned economies. Quite the contrary, by cutting the supply-demand-price feedback loops and converting price to a policy variable one could use the model to examine the systemic implications of various price policies for old and new technology products. This could be very useful to a planning agency that wishes to know how government price policies affect and could affect the transition from one technology to another.

\section{Learning in the Context of Technological Substitution}

The real world context in which technical learning occurs is complex and variable. However, there are sufficient regularities of form to permit simplification and generalization. Here learning is observed in the context of the interaction between two production systems that compete for market shares. In the paragraphs that follow we first describe that context and then note how learning affects it. In the envisioned structure each competing production system can increase output by expanding capacity. Output increase, as transmitted through market mechanisms and cost accounting equations, influences both further capacity accumulation (through profits) and that portion of consumer purchasing habits (i.e., market share changes) that is price determined.

A causal influence scheme for the structure described thus far is shown below in Figure 1. The two pairs of central loops passing through sales describe the growth thrusts by which each system might expand. Capacity growth leads to growth of outputs and then 


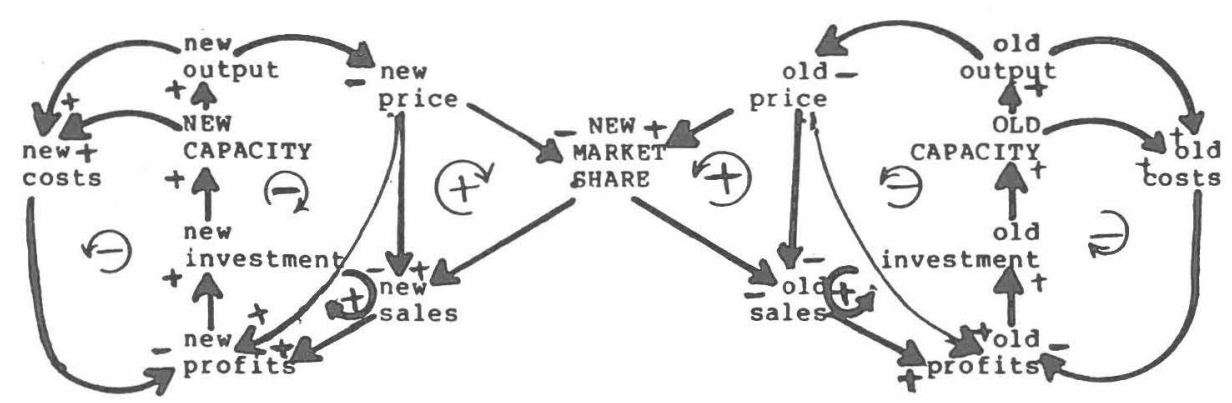

Fig. 1. Competitive structure within which technological substitution takes place.

to decreased prices, increased demand and increased profits, and finally increased investment and enlarged capacity. This is the drive behind the capacity accelerator of neoclassical economics.

The outer loops and the light inner lines show cost and price effects that counterbalance these growth forces. Fixed costs increase with capacity and variable costs with output. Expended output causes lower prices. Lower prices and higher costs cut into profits and thus reduce investment. Of course, reality is much more complex. Prices and sales expectations may influence capacity utilization, factor prices may change, and dozens of other things might be added. These could be incorporated into the model. For clarity, we omit them here.

Learning curves are easily linked into this structure. For the purpose of this paper a learning curve is any functional relationship between a measure of performance and a measure of experience. Thus it corresponds to what some $[14,15]$ term a progress function, and does not necessarily imply that learning is encoded in a human brain. Here, initially, learning is explicitly formulated as a functional relationship between cumulative output and cost per unit output. The relationship is presumed to take a conventional nonincreasing form, as shown in Figure 2.

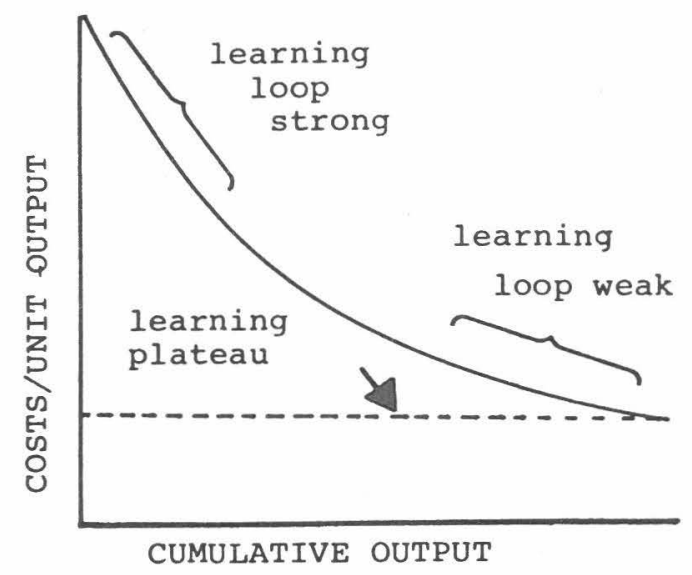

Fig. 2. A learning curve. 
In the model posed above cumulative output is easily calculated by accumulating output figures and can be used to drive production costs through the learning curve. This linkage, as shown in Figure 3, sets up a positive feedback loop that will begin to lose strength as the learning process moves into regions of diminishing returns.

Given that the learning loop is strong when cumulative output is low and uninfluential when learning tapers off, new technologies, which tend to be less far along in the learning process, will be subject to more vigorous learning growth than their older competitors. Therefore when the learning loop is added to the above model, the model's apparent symmetry disappears. Stripping Figure 1 down to its capacity acceleration loops and adding learning loops with size proportional to strength yields a system like that shown in Figure 4.

The behavioral tendency created by adding learning loops to this system is consistent with the logistic growth process usually observed in the course of technological substitution, and seems a plausible model for historically observed patterns such as that shown in Figure 5 for electricity. As the new technology starts out, learning provides it with a powerful dynamic thrust, and by cutting prices while sustaining profits it intrudes upon the market of the old technology. As the new technology matures and its learning processes slow down, restraints take over and its growth ceases.

\section{INSIGHTS ON SHAPE}

Almost any way one formalizes the patterns of causation described above leads to the conclusion that the course of technological substitution is strongly influenced by the shapes and parameters of the old and new technology's learning curves. I have generally found that these questions are relative and not absolute, that the key question is not the form of a new technology's learning curve but rather the relative forms of the old and new technology's learning curves. Three aspects prove noteworthy: initial efficiency, slope (rapidity of efficiency gain), and ultimate efficiency (point of diminishing returns).

The importance of initial efficiency is easily demonstrated by making extreme assumptions. If, for example, one uses a hyperbolic function for the learning curve, the costs of producing the first unit of output are infinite while the costs of producing later units of output will approach zero as cumulative output became very large. Under these conditions, quite clearly, no new technology could ever become established! Even if initial costs are finite but relatively high-for example 10 times those of the old technology, the new technology will be unable to meet costs and will face heavy losses (unless high prices can be sustained). These losses, in turn, make it difficult for the new technology to procure investment.

If, on the other hand, initial costs are very low-for example if they are half those of

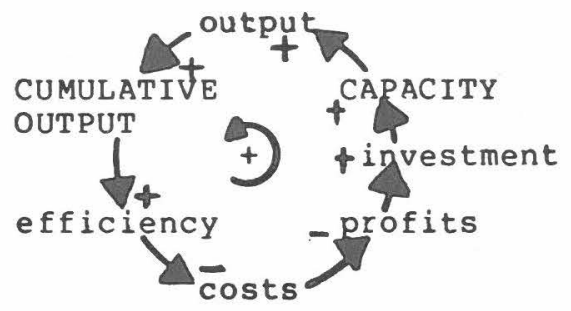

Fig. 3. A learning loop. 


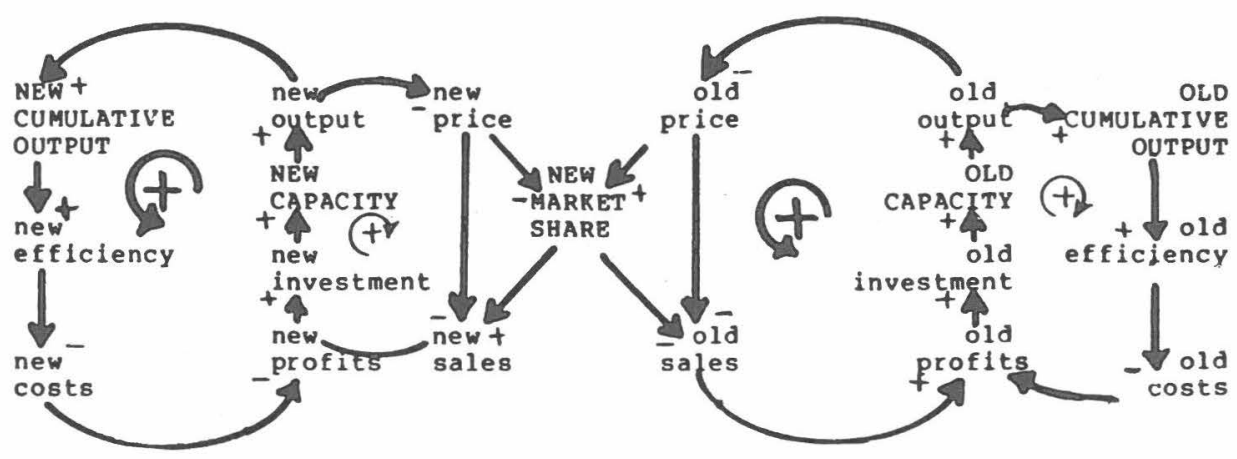

Fig. 4. The forces of technological substitution with learning added.

the old technology - the new technology will immediately show large profits, which will lead to heavy investment, flooded markets, and serious price depression.

Casual observation confirms the above structural deductions. In real situations there has been great variation in the range of relative efficiencies at which new technologies have entered the market. Where entry efficiency is too low the innovation fails, unless it can find a special market niche in which it can meet its high costs by charging high prices [17]. For example, plastics appeared as substitutes for high-cost materials such as whalebone and tortoiseshell before they began to be used in bulk as substitutes for glass, metal, ceramics, and wood. Where entry efficiency has been high, as for example in the case of competition between natural and synthetic ice in hot climates, or between batch and continuous flow operations, the new technology has grown rapidly and its growth has typically resulted in what are euphemistically called disorderly markets [10, Ch. 4].

After the importance of the relative initial production efficiency of the new technology is noted, attention naturally moves to the relative plateau values of old and new technology efficiency, that is, to the ratio of asymptote toward which new technology production efficiency moves as cumulative output approaches infinity to the equivalent asymptote for the old technology.

Here again it is intuitively clear that the parameter varies greatly between innovations and that the variation has important consequences for the process of technological substitution. The relative ultimate production efficiency of computers as opposed to manual computation is best measured in powers of 10 . The relative ultimate production efficiency of mechanized fruit picking as gauged against manual picking will vary with definition and factor prices, but it is probably not far from unity. This helps explain why market penetration of mechanized fruit harvesting pattern has been slow and limited to places where labor costs are high and why the potential long term impact of computers on society is very high. (In general, where relative plateau values are close to unity, factor prices become more important in technological substitution.)

In sum, the parameters of the production efficiency learning curve can be likened to those of a chemical chain reaction. The relative initial production efficiency of a technology functions like an energy of activation. ${ }^{1}$ If it is above 1 , the substitution is vigorous and

\footnotetext{
${ }^{1}$ For many chemical reactions, including combustion, a certain energy input, like lighting a match, is needed to initiate the reaction. Thereafter the reaction releases sufficient energy to keep itself going. The energy that must be put in is called the activation energy, and the energy that is produced is called the energy of release.
} 


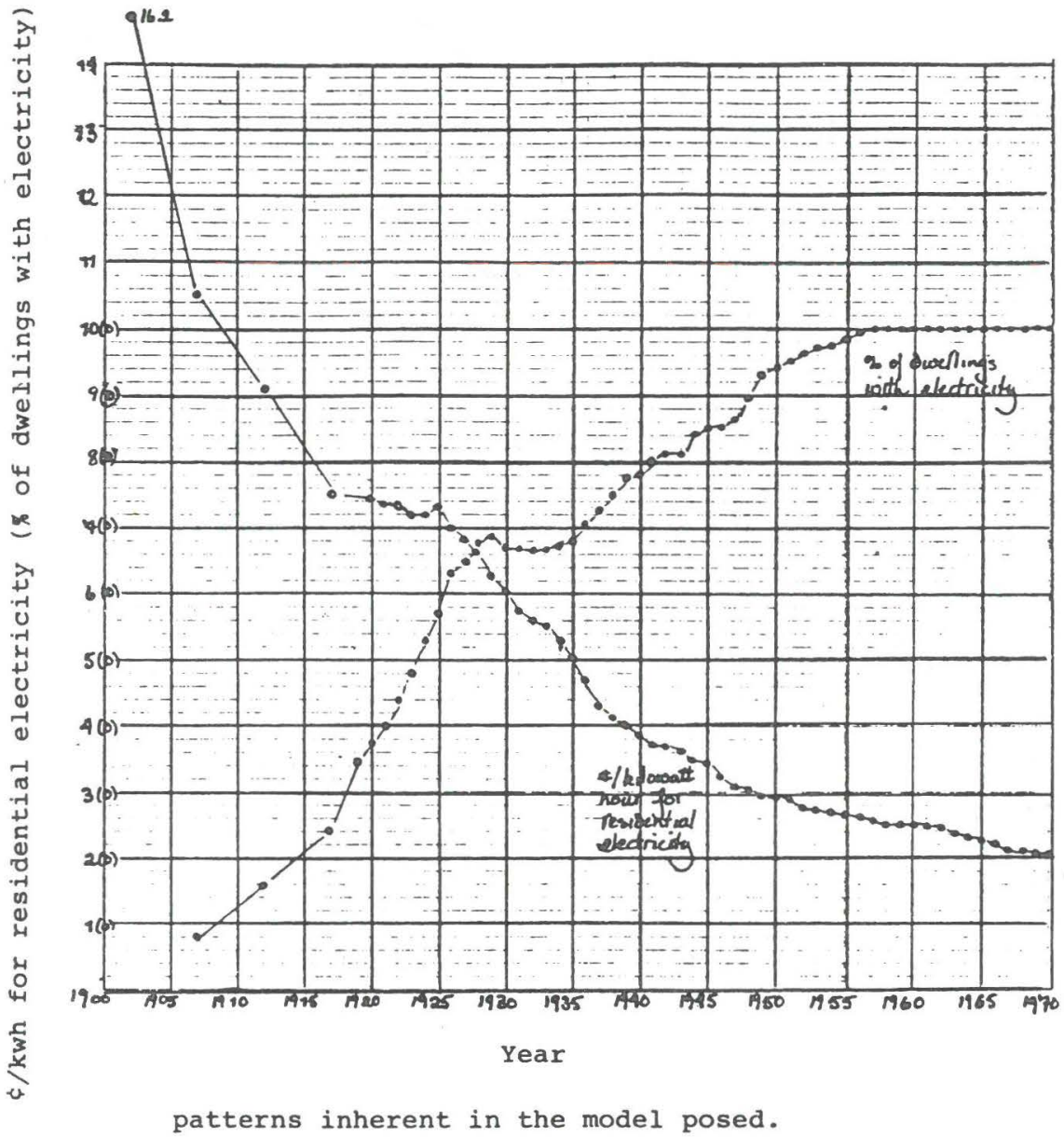

Fig. 5. Electricity costs and percent of dwellings with electricity in the United States: An example of the time patterns inherent in the model posed. Source: U.S. Bureau of the Census [16].

self-starting; when it is below 1, the process will only be set off by special circumstances, such as a localized situation in which the parameter is above unity, an especially able manager who is able to force rapid learning, or policy measures such as creation of guaranteed markets that create a niche for the new product.

Some combination of the slope of the curve and its height relative to that of the competing technology determines the energy of release and the rate of reaction. That is, it establishes the vigor with which the new technology enters competition and gains market share and the extent of the changes affected by the technology's introduction.

\section{MARKETING PROGRESS}

Innovation and learning have a qualitative as well as an efficiency dimension; that is, they affect consumers' willingness to pay as well as production costs. The qualitative dimension is a composite that is hard to measure and compare. Nonetheless, something can be deduced about its general form. Many objective indices of product quality, includ- 
ing speed, power, precision, size, and defective rates, can be shown to follow learningcurve-type patterns because producers tune technology to suit market preferences. If they were more often measured, subjective indices such as comfort, convenience, and in some cases even status value could probably also be shown to follow learning curve forms. As a composite of learning curve forms we can expect that willingness to pay will also follow a learning curve.

Learning here may entail at least three different processes occurring singly or in combination. First, consumers may learn to like the product; that is, they may either overcome ignorance about its use or prejudices against it, or a "keeping up with the Joneses" pattern may make the new product a status symbol. Second, the product's support infrastructure may develop in a way that makes the product more useful; for example, a buildup of paved roads made automobiles more useful and a buildup of broadcasting capabilities enhanced the value to the consumer of radio and television. Third, producers may make the product more attractive or more available by product innovation, rationalization of marketing channels, or improvement of product-associated services and advertisement. All three processes will have the effect of increasing the rate at which consumers shift their purchases toward the new technology as it accumulates experience.

The exact mechanisms by which this process occurs probably differ. Consumers' experience with a new product and infrastructure development are probably associated with cumulative sales or cumulative product usage, while the form of experience leading to product improvements is probably more closely associated with cumulative investment. However, because the various possible measures of experience will behave in a fairly similar fashion, it is justifiable to aggregate the separate processes into a single feedback loop linking cumulative output to expansion of market share, as shown in Figure 6. As with the production efficiency learning loop this reinforces the capacity acquisition growth loops with additional positive feedback. By increasing new technology sales and market share this loop also tends to raise the new technology's price level, which further stimulates profits and growth.

The matters of form discussed in relation to the learning curve for production efficiency apply well to the sales efficiency learning curve. If the new technology's initial

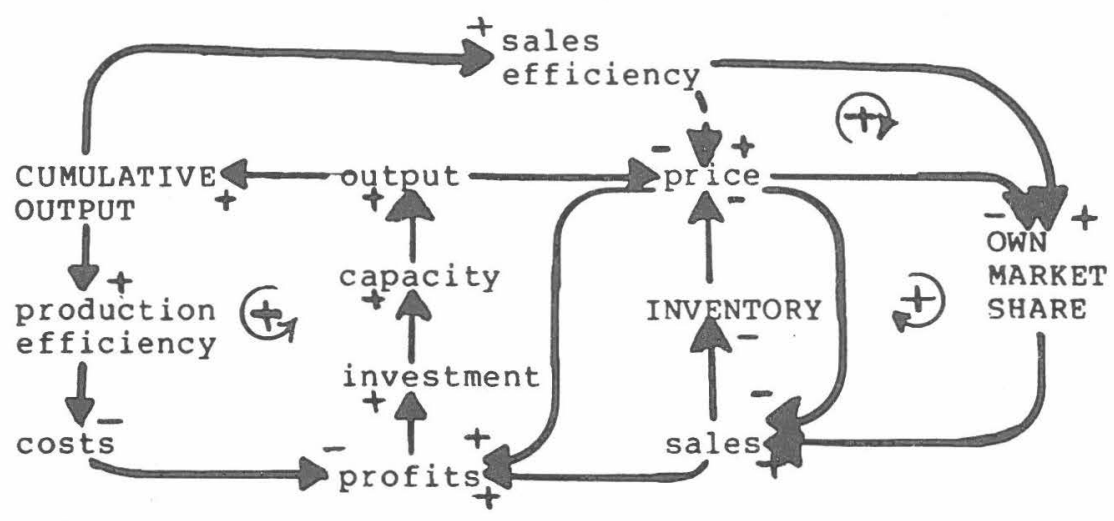

Fig. 6. The growth loop of one competing technology with market learning added. 
sales efficiency is too low relative to that of the old technology the loop acts as a constraint. Low sales efficiency prevents market expansion, which leads to losses and no investment. Lack of investment prevents both output expansion and expansion of markets through gains in sales efficiency. If, however, this constraint can be overcome the vicious circle becomes a snowball effect. Learning gains spur on further growth and further learning gains until such time as the system reaches a point of diminishing returns and learning ceases to contribute much to further growth.

Similarly, the vigor with which the new technology invades the old technology's market and the size of barrier it will present to new technologies that might later threaten its market share depend on the height and slop of its market learning curve.

In simulation I find that market-directed learning tends to be a more powerful force than process efficiency learning. This appears to be because market-oriented learning tends to increase demand more rapidly than supply, thus leading to high prices, high profits, and rapid investment. Process efficiency gains, on the other hand, tend to increase supply faster than demand, thus leading to price cutting, low profits and low investment. In other words, the negative feedback associated with process efficiency gains is stronger than that associated with market efficiency gains.

\section{IMPLICATIONS OF TWOFOLD LEARNING PROCESS}

In the context of the structure posed, both kinds of learning can be very powerful influences pushing and restraining the process of technological substitution. When the two occur simultaneously the power of each is magnified. In the real world both types of learning take place with development of a new technology, with the distribution of the two being a function both of the product's social function and of the scope for product and process variation. Production efficiency learning is probably more important for commodities, such as electrical power, sugar, or cement, where products are of a pure and uniform nature. Market learning generally prevails with complex diversified roles and where functional specialization and/or pyschological and taste components have important bearing on the product's value to the purchaser (e.g., machinery and electronic equipment, and consumer goods).

Macroeconomic factors also affect the respective strategic values of process and market learning. Process learning is most important in circumstances of poverty and scarcity. Where willingness to pay heavily is constrained by ability to pay, increasing supply and decreasing costs are likely to lead to higher levels of basic consumption rather than glutted markets. Market learning is more critical in circumstances of affluence and plenty.

The above discussion may have sounded like it pertains to consumer goods only. However, rising incomes probably lead to increased emphasis on market learning for producer goods as well, for two reasons. First, the pressure for diversified, user-oriented consumer goods forces managers to deal with more complex situations in which they place much more exacting specifications on the equipment they use. It becomes more critical whether the machine will perform the task required reliably and precisely than how much the machine costs. A machine with a purchase price of $\$ 50,000$ that fits smoothly into the production line is to be preferred to a $\$ 5000$ bottleneck.

Second, market learning is a good strategy for averting the competitive pressures of a market dominated by efficiency learning. For example, as the market for computer chips becomes increasingly flooded, the advantage turns toward the firm that develops attractive 
user-oriented software. Here market learning can permit the maintenance of favorable prices even with a flood market.

The supposition that market learning becomes more important as incomes rise leads to an important digression. If this supposition is true and in the last few decades the developed countries have undergone an overarching transition toward market as opposed to production learning, one would expect to see a fundamental, though perhaps subtle, change in the nature of technological change. Instead of more efficient basic machinery one would expect more sophisticated and diversified techniques and design improvement, criteria of convenience, and consumer appeal to prevail over efficient quantity production.

It remains for me a nagging question whether the current sense of technical slowdown is indeed a real slowdown or simply a change in direction. Are we really faced with a technological stalemate [8], or have we simply outgrown one phase of technical development and moved on to another?

\section{Technological Change}

As a dilettante evolutionary biologist, I laugh at the images posed above for the simple, naive Darwinism. Extend the model and one envisions a world mechanistically and teleologically moving toward greater efficiency and sophistication through the forces of innovation (mutation), learning (natural selection), and competition.

The world you and I inhabit is at once more complex and wonderful than the competitive model posed above and much less certain of progressing toward a state of happy perfection.

Concerning the complex and wonderful, the system is not simply dog eat dog. Coevolutionary processes based on mutualism and complementarity between innovations are probably as important in technological change as are competitive evolutionary trends. Such patterns are repeatedly described in David Landes' epic work The Unbound Prometheus [6] and are given the name "technological convergence" by Nathan Rosenberg [13]. Landes (p. 86), for example, describes a sequence in which the flying shuttle and other improvements in weaving technology created economic pressure for faster and greater spinning production. This led to the invention of the spinning jenny and the spinning mule. These were so efficient that they placed pressure both on weaving and on the cleaning and sorting of fibers. Two similar examples from the present century are as follows. Electrification created opportunities for a large number of mechanical innovations, and the diffusion of multiple electrical innovations created a demand for electricity. Product diversity created a niche for modern retailing technologies, such as supermarket chains, and supermarkets provide orderly and efficient marketing for a diversified spectrum of goods [10, Ch. 4].

Concerning the less wonderful, there is no reason to believe that progressive learning of a system's parts is consistent with the welfare of the whole. As Garrett Hardin dramatically pointed out in "The Tragedy of the Commons" [5], situations in which all decision makers optimize individual benefits can lead to destruction of the resource base of the system as a whole. The general efficiency-optimizing trends found throughout the whole of technology may well lead the technosphere into patterns of development that can neither be sustained nor reversed without traumatic reorganization.

Energy is a case in point. Many technosystems (ecosystem plus technology) spent the last few centuries with many of their parts optimizing under conditions of cheap energy and the whole of developed country economics evolved in energy intensive directions. 
Today it appears that the net effect of that trend may have been to undermine the technical basis of Western civilization by depleting energy supplies faster than technology can adapt to energy scarcity - or to increase the $\mathrm{CO}_{2}$ concentration in the atmosphere in a fashion that will seriously affect the earth's climate.

Reduction of diversity poses another sort of problem. Efficient fine tuning of an ecosystem's organisms may make the whole inflexible and vulnerable to catastrophe. It is, for example, speculated that waves of extinction, such as that which eliminated the dinosaurs, were brought about by a process of natural gene-pool narrowing during geologic epocs with monotonous climate and landscape [1]. Many plant geneticists fear that the modern reliance on increasingly uniform strains of a dozen or so food plant species has purchased high efficiency at the cost of introducing high genetic vulnerability $[2,9]$.

Genetic burden may be another case. The proliferation of complex synthetic chemicals and radioactive material brought about by 20 th century technologies increases the probability of mutation. Many mutations are sublethal and thus are passed on from generation to generation. In the absence of natural selection-and the number of human beings who fail to live to reproductive age is too low in the developed world to permit natural selection - the number of minor sublethal genetic defects in the human population can only increase. This, in theory, will inevitably lead to a higher incidence of birth defects and a general decline in human health.

Although the comprehensive work on the subject has yet to appear, there seems to be a prevailing hunch among scholars working on technological innovation $[3,4,7]$ that the cycles of innovations and the Kondratief wave are somehow linked to a tendency of many technological trends to reach learning plateaus together. If this indeed proves to be the case, it would be another case where uncontrolled learning of subsystems is destabilizing to the system as a whole.

This evokes a closing observation that in the next decades and centuries the most important learning curve for humanity may not be that of the market or of production, but of system control. The largest technical substitution in the last several centuries has been the substitution of human-controlled technical processes for natural ones. All too often this means replacement of a passive system with intricate and effective homeostatic capabilities by an aggressive but poorly balanced system. In many places such substitutions have undermined or threatened to undermine life support systems. For most of the world's people they have failed to bring a substantial increase in the material standard of living. It is fairly clear that free-form growth of technical systems will not eliminate these problems. It remains to us to create a viable alternative.

\section{References}

1. Bakker, R.T., “Dinosaur renaissance," Sci. Am. (April), 58-78 (1975).

2. Barney, G.O., et al., Entering the 21st Century: Report on the Global 2000 Study to President Carter, technical column, U.S. GPO, Washington, D.C., 1980.

3. Forrester, J.W., "Innovation and the Economic Long Wave," System Dynamics Group Paper No. D-2990-1, Sloan School of Management, Massachusetts Institute of Technology, Cambridge, Mass., November 1978 .

4. Graham, A.K., and Senge, P.M., “A Long-Wave Hypothesis of Innovation," Technol. Forecast. Soc. Change 17, 283-311 (1980).

5. Hardin, G., "The Tragedy of the Commons," Science 162, 1243-1248 (1968).

6. Landes, D.S., The Unbounded Prometheus, Cambridge Univ. P., London, 1969. 
7. Klein, B., Dynamic Economics, Harvard Univ. P., Cambridge, Mass., 1979.

8. Mensch, G., Das Technologische Patt: Innovationen Übertwinden die Depression, Umschau Verlag, Frankfurt, 1976.

9. National Research Council, Genetic Vulnerability of Major Crops, National Academy of Sciences, Washington, D.C., 1972.

10. Robinson, J.M., "The Mechanics of Diet: The Relationship Between Technological Change and Diet in U.S. History 1900-1975," M.S. thesis, Univ. Illinois, 1977.

11. Robinson, J.M., “Technological Shift: A Cybernetic Exploration,"' WP-79-104, IIASA Laxenburg, Austria, 1979.

12. Robinson, J.M., "Technological Shift: A Graphical Exploration of Progress Functions Learning Costs and Their Effects on Technological Substitution,'” WP-79-105, IIASA, Laxenburg, Austria, 1979.

13. Rosenberg, N., Perspectives on Technology, Cambridge Univ. P., New York, 1974.

14. Sahal, D., "Recent Advances in a Theory of Technological Change," International Institute of Management, discussion paper series dp/79-11, Berlin, 1979.

15. Sahal, D., “A Theory of Progress Functions,"' Trans. AAIE, in press.

16. U.S. Bureau of the Census, Historical Statistics of the United States, Colonial Times to 1970, bicentennial ed., Pt. 2, Series S108-119, U.S. GPO, Washington, D.C., 1975.

17. Utterback, J.M., "Business Invasion by Innovation," Center for Policy Alternatives Working Paper 73-13, Cambridge, Mass., 19 August 1978.

18. Yelle, L.E., "The Learning Curve: Historical Review and Comprehensive Survey," Decision Sci. 10, 302-330 (1979).

Received 18 February 1980 
